\title{
Aquicultura, Política e Meio Ambiente no Brasil: Novas Propostas e Velhos Equívocos
}

\author{
Dilermando Pereira Lima Junior ${ }^{1 *}$, Fernando Mayer Pelicice ${ }^{2}$, \\ Jean Ricardo Simões Vitule ${ }^{3}$ \& Angelo Antonio Agostinho ${ }^{4}$
}

\author{
${ }^{1}$ Programa de Pós-Graduação em Ecologia de Ecossistemas Aquáticos Continentais, \\ Universidade Estadual de Maringá - UEM, Maringá, PR, Brasil \\ ${ }^{2}$ Núcleo de Estudos Ambientais, Universidade Federal de Tocantins - UFT, Porto Nacional, TO, Brasil \\ ${ }^{3}$ Laboratório de Ecologia e Conservação - LEC, Departamento de Engenharia Ambiental, Setor de Tecnologia, \\ Universidade Federal do Paraná - UFPR, Curitiba, PR, Brasil \\ ${ }^{4}$ Departamento de Biologia - DBI, Núcleo de Pesquisas em Limnologia, Ictiologia e Aquicultura - NUPELIA, \\ Universidade Estadual de Maringá - UEM, Maringá, PR, Brasil
}

"Those who do not learn from the past are destined to repeat it." George Santayana

\section{Introdução}

Já dizia o dito popular que desgraça pouca é bobagem. Atualmente vemos o nosso Poder Legislativo fazendo modificações em pontos relevantes do Código Florestal, mesmo diante de argumentos contrários que mostram o quão deletérias essas mudanças serão (Metzger 2010). Não bastasse isso, mais uma ameaça ambiental chama a atenção das pessoas que se preocupam com a conservação e uso racional dos ecossistemas brasileiros. O foco agora é dirigido diretamente sobre a integridade dos ecossistemas aquáticos, já bastante ameaçado pelas mudanças propostas no Código Florestal (Magalhães et al. 2011) e expansão da usinas hidroelétricas em todo o território nacional.

Na Câmara dos Deputados tramita um Projeto de Lei (PL) que, se aprovado, pode causar grandes prejuízos à conservação dos recursos e ecossistemas de água doce brasileiros. A Comissão de Agricultura, Pecuária, Abastecimento e Desenvolvimento e a Comissão de Meio Ambiente e Desenvolvimento Sustentável aprovaram o Projeto de Lei do deputado Nelson Meurer (PP-PR) que incentiva a criação de espécies não-nativas em tanques-rede, equiparando-as às espécies nativas do local (Projeto de Lei 5989/09). Na proposta original, espécies não-nativas de alto potencial invasor, mas com grande interesse para cultivo e para o comércio de alevinos, como a carpa cabeça grande (Aristichthys nobilis), carpa capim (Ctenopharyngon idella), carpa comum (Cyprinus carpio), carpa prateada (Hypophthalmichthys molitrix) e tilápia do

\footnotetext{
*Send correspondence to: Dilermando Pereira Lima Junior Programa de Pós-Graduação em Ecologia de Ecossistemas Aquáticos Continentais, Universidade Estadual de Maringá, Av. Colombo, 5790, CEP 87020-900, Maringá, PR, Brasil E-mail: dilermando.lima@gmail.com
}

Nilo (Oreochromis spp.), entre outras, seriam legalmente "naturalizadas" no intuito de permitir a criação das mesmas em águas continentais brasileiras, principalmente em modalidade de cultivo de tanques-rede ou estruturas similares. No substitutivo do relator, deputado Carlos Magno (PP-RO), a nominação das espécies foi retirada e deixado ao Ministério da Pesca e Aquicultura a determinação das espécies exóticas que se enquadrariam nessa liberação. A questão do prévio estabelecimento no ambiente foi omitida e a proibição de solturas ficou restrita apenas às espécies aquáticas geneticamente modificadas. Em suma, modificou-se o artigo 22 da Lei 11959 de 2009 que estabelecia que na

“[...] criação de espécies exóticas, é responsabilidade do aquicultor assegurar a contenção dos espécimes no âmbito do cativeiro, impedindo seu acesso às águas de drenagem de bacia hidrográfica brasileira." (Brasil 2009a)

e revogou-se as leis anteriores sobre o tema. Como suposta contrapartida ambiental, o mesmo projeto obriga os proprietários ou as concessionárias a efetuarem o repovoamento (estocagem) de reservatórios com espécies nativas e sugere outras medidas complementares a serem indicadas pelo Ministério da Pesca e Aquicultura. Transcrevemos abaixo alguns trechos da proposta onde problemas reais e soluções equivocadas são mesclados de forma perigosa:

"[...] A criação de peixes em tanques-rede é um dos sistemas mais intensivos em uso na atualidade. Sua prática tem-se popularizado em virtude do fácil manejo, da elevada produtividade e do investimento inicial relativamente baixo. Ao equiparar a criação de algumas espécies de peixes em tanques-rede à criação de peixes autóctones, pretende-se afastar obstáculos normativos à produção das espécies sugeridas." (Brasil 2009b) 
“[...] Os rios e lagos brasileiros, outrora piscosos, deixaram de sê-lo, em razão de vários fatores, tais como: a degradação ambiental, a pesca predatória e a construção de barragens. A redução da produtividade pesqueira é um fenômeno que se verifica em todo o país, não só em águas continentais, mas também no ambiente costeiro." (Brasil 2009b)

"[...] A pesca é uma atividade de extrema importância social e econômica, sendo imperativa a adoção de medidas que promovam o incremento de sua produtividade. Neste sentido, devem considerar-se medidas de proteção ambiental, ordenamento pesqueiro, incentivo à aquicultura e repovoamento dos ambientes aquáticos, para que voltem a tornar-se piscosos [...]" (Brasil 2009b)

Infelizmente problemas ambientais complexos não têm soluções simples e não é possível manipular habitats ou populações naturais sem riscos. A baixa rentabilidade da pesca e o virtual desaparecimento de várias espécies de peixes de grande porte nos trechos altos da bacia do rio Paraná, após mais de 30 anos dos programas de repovoamento, são emblemáticas em relação a isso. $\mathrm{O}$ apelo pela aquicultura e repovoamento como formas de mitigação ou compensação de impactos de represamentos ainda esbarra em problemas ambientais (Agostinho et al. 2010). Destaca-se, nesse aspecto, que a aquicultura é a principal responsável pela introdução de espécies não-nativas de peixes de água doce no Brasil e no mundo (Naylor et al. 2001), sendo as espécies introduzidas consideradas importantes vetores de perturbações. São vários os exemplos na literatura científica que mostram como a introdução de peixes não-nativos por aquicultura vem seguida de impactos negativos que atingem desde o nível de indivíduo até ecossistemas (Cucherousset \& Olden 2011 para uma revisão atual sobre o tema). Em relação às espécies referidas no PL 5989/09, destacam-se impactos relevantes como a modificação da qualidade da água e do habitat e competição com espécies nativas (Zambrano et al. 2001; Canonico et al. 2005). Tantos e tão graves são esses impactos que quatro das espécies (Ctenopharyngodon idella, Cyprinus carpio, Hypophthalmichthys molitrix e Oreochromis niloticus) relacionadas no PL 5989/09 são classificadas dentre as 100 mais perigosas invasoras de ecossistemas continentais de água doce do mundo. Um exemplo emblemático foi a invasão de carpas nos grandes lagos norte americanos. Esta invasão problemática levou o governo dos Estados Unidos a uma série de medidas no sentido de controlar sua expansão, sem, contudo, alcançar nenhum resultado significativo. Assim, a aprovação do PL 5989/09, ao negligenciar o conhecimento já disponível, em escala global, acerca dos impactos negativos das invasões biológicas, assume a clara opção por uma possível produção econômica a qualquer custo ambiental. O monitoramento da captura por unidade de esforço da pesca profissional realizado no reservatório de Barra Bonita (rio Tietê), entre 1991 e 2006, mostra que o incremento da tilápia nos desembarques, verificado a partir de 2004, se deu em detrimento das espécies nativas (AES Tietê 2007).

\section{Riscos Ambientais do PL 5989/09}

Como mencionado, o PL em tramitação "[...] pretende afastar obstáculos normativos.” (Brasil 2009b) ao cultivo em tanques-rede de peixes não-nativos nos reservatórios brasileiros. Dois aspectos principais devem ser ressaltados nessas discussões, um inerente ao caráter universal dos escapes nesse tipo de cultivo e o outro que destaca as peculiaridades dos reservatórios que facilitam o estabelecimento de novas espécies e sua dispersão na bacia.

Embora o PL em tramitação trate do cultivo de peixes em regime de confinamento em tanques-rede, sendo esperado que o manejo adequado desses tanques deva impedir escapes, na prática é consenso que os escapes são inevitáveis (Agostinho et al. 2010). Em trabalho recente, Azevedo-Santos et al. (2011) entrevistaram aquicultores no reservatório de Furnas e constataram que escapes acontecem em todas as propriedades, em diferentes fases do cultivo, por diferentes razões (acidentais e/ou deliberados). Em outras palavras, mesmo em sistemas consolidados de cultivo (e.g. Furnas), escapes acontecem - um aspecto não considerado pelo PL 5989/09. É importante destacar que a magnitude dos impactos ambientais de espécies invasoras depende da sua dinâmica demográfica e da pressão de propágulos. Escapes frequentes e/ou intensos podem causar novos impactos ou agravar problemas antes imperceptíveis, podendo ocorrer explosões populacionais e colonização de ambientes contíguos.

Mesmo que fosse garantida a eficiência total no confinamento das espécies nos tanques, isso não impede a ocorrência de outros problemas ambientais. É comum que, associado à introdução e estabelecimento de peixes não-nativos, ocorram estabelecimentos secundários devido à introdução de espécies acompanhantes. A introdução de parasitas é o exemplo mais claro disso e há estudos que mostram os impactos negativos de ordem econômica e ecológica (Peeler \& Feist 2011), incluindo no Brasil. Além disso, impactos de outra natureza, porém registrados rotineiramente em sistemas de cultivo, foram também desconsiderados, como a deterioração da qualidade da água, agregação externa de fauna nativa e alterações na sua dieta, além de conflitos sociais no uso do espaço físico (Dempster et al. 2004).

Em relação ao ambiente alvo do $\mathrm{PL}$, os reservatórios, o fato dos mesmos serem ambientes alterados e sujeitos a distúrbios periódicos cria condições propícias ao estabelecimento de novas espécies, mais tolerantes e/ou oportunistas (Johnson et al. 2008). Soma-se a isso o fato de um reservatório não ser uma ilha isolada no espaço, e que animais nele liberados podem, por dispersão, atingir corpos d'água contíguos, como rios, córregos e outros reservatórios - incluindo aqueles em que o invasor ainda não se estabeleceu. Com isso, reservatórios devem facilitar o processo de invasão, por funcionarem como "trampolins ecológicos" para o estabelecimento, dispersão e expansão de área de espécies não-nativas invasoras (Havel et al. 2005). Assim, espécies não-nativas, como as rústica tilápia, cultivadas em ambientes que favorecem o processo invasivo, ampliam as possibilidades de alcançarem áreas protegidas como unidades de conservação (UC's). Fica evidente que a liberação como proposta no PL potencializará o processo de 
invasões biológicas nos ecossistemas aquáticos interiores, uma vez que todos os reservatórios do Brasil serão passíveis de introdução proposital e/ou acidental.

A proposta inicial condicionava a permissão do cultivo de espécies não-nativas somente em reservatórios onde elas já estivessem estabelecidas. Mesmo assim, a justificativa original não julgava essa condicionante como relevante, como mostrado na transcrição abaixo.

"[...] No que concerne à aquicultura, entendemos devam ser priorizadas as espécies já estabelecidas no ambiente aquático onde se localiza o empreendimento. Entretanto, devem ser evitados maiores empecilhos normativos à criação, em tanques-redes ou estruturas assemelhadas, instaladas em reservatórios de águas continentais, de determinadas espécies não predadoras, de alto potencial produtivo e presentes há muitas décadas em águas brasileiras, como a carpa e a tilápia [...]” (Brasil 2009b)

Isso foi assumido no substitutivo proposto pelo relator, que suprimiu a condicionante. Entretanto, mesmo com a condicionante inicial a proposta tem riscos implícitos. O primeiro seria a falta de critérios ou de informações suficientes para identificar inequivocamente as espécies estabelecidas. O outro é decorrente do fato de liberações suplementares poderem aumentar a densidade da invasora, assegurando sua persistência como população viável e potencializando os impactos sobre as nativas. Assim, a justificativa é desprovida de qualquer fundamentação científica. Pelo contrário, novas introduções implicam em aumento da pressão de propágulos que pode tornar espécies meramente estabelecidas em invasoras problemáticas. Também, estudos sugerem que espécies não-nativas onívoras e herbívoras podem causar impactos ambientais tão adversos quanto aqueles causados por espécies predadoras ou ainda maiores (Cucherousset \& Olden 2011), pois as primeiras têm elevado potencial em alterar a qualidade da água e do ambiente. Além disso, predação não está restrita à ingestão de peixes jovens ou adultos. Ela também ocorre quando o consumo envolve os ovos e as larvas.

O outro ponto crítico do PL 5989/09 relaciona-se à obrigatoriedade do repovoamento anual dos reservatórios com espécies nativas. Essa prática vem sendo conduzida há mais de 30 anos em reservatórios da bacia do alto rio Paraná sem resultados eficazes, provavelmente devido a não observância de premissas básicas para a sua implementação (Agostinho et al. 2010). A sua banalização como estratégia de manejo tem, como a de qualquer tipo de biomanipulação, elevado risco ambiental, destacando-se aqueles associados à introdução espécies não-nativas (patógenos, parasitas ou mesmo outras espécies de peixes) e degradação genética dos estoques naturais, dentre outros (Agostinho et al. 2010). Assim, a solução de manejo proposta (i.e. estocagem) deve ser decidida com base em amplo conhecimento do sistema, atender a demandas claras dos estoques, e ser executada de forma a evitar impactos genéticos, de sanidade ou nas relações interespecíficas vigentes. Esses requisitos são incompatíveis com o caráter compulsório da estocagem previsto no PL.
A obrigatoriedade das estocagens anuais de peixes em reservatórios é justificada, na proposta, pela dramática redução dos estoques pesqueiros em águas interiores. Contudo, não existe solução simples para essa catástrofe ambiental, considerando que a degradação dos ecossistemas aquáticos do país deriva, sobretudo, das alterações irreversíveis de habitat decorrente dos represamentos e, provavelmente, dos próprios programas de estocagem que inicialmente foram realizados com espécies não-nativas. De qualquer maneira, o argumento utilizado para justificar a obrigatoriedade da estocagem é, ao mesmo tempo, um forte indicativo de que ela não é a solução. A depleção dos estoques de peixes na bacia do alto rio Paraná ocorreu sob a vigência de programas intensivos de repovoamento patrocinados por todas as grandes concessionárias de energia com atuação nesse segmento da bacia (Agostinho et al. 2010). Pode-se afirmar que as propostas básicas contidas no Projeto de Lei em tramitação apresentam soluções de ordem puramente econômicas e imediatistas (e.g. produção de pescado, produção de alevinos) para sanar problemas de ordem ambiental e social de longo prazo (e.g. perda de biodiversidade e recursos naturais). Não existe, portanto, sintonia entre a natureza do problema e a natureza da solução. Dado que os problemas estão relacionados a alterações de habitat e espécies não nativas, seria mais lógico imaginar que a solução para os estoques depauperados das espécies nativas devesse focar sobre esses componentes, como por exemplo, o manejo de habitat (incluindo manutenção de áreas lóticas a montante dos reservatórios, restabelecimento sazonal de vazões adequadas) e prevenção-controle de populações de espécies não-nativas.

\section{Paradoxo Brasileiro}

O incentivo para produção de peixes não-nativos no Brasil é algo um tanto paradoxal, pois enquanto o país abriga algumas das mais diversas regiões ictiofaunísticas do planeta (ainda com muitas espécies desconhecidas), toda sua base de produção aquícola é fundamentada em espécies e pacotes tecnológicos importados. Atualmente mais de $85 \%$ da produção nacional é baseada em espécies provindas de outros países e/ou continentes, o que torna o Brasil, proporcionalmente, o maior produtor mundial de espécies não-nativas. $\mathrm{O}$ fomento à aquicultura brasileira está focado na produção ou mesmo na pesquisa de espécies não-nativas, sendo claramente reduzida a atenção dada ao desenvolvimento de tecnologias para o cultivo de espécies nativas. Em relação a essas últimas, pesa ainda o esforço em se fomentar o cultivo comercial antes que as técnicas de produção estejam consolidadas, levando à descrença do potencial dessas espécies para a aquicultura. Nesse aspecto, aparece outro paradoxo: se existe tecnologia para produção de alevinos nativos em escala suficiente para sustentar programas de repovoamento em todo território nacional, que empecilhos existiriam para se estabelecer um programa pesquisa, melhorando o desempenho zootécnico e de produção de peixes nativos? Os gestores e toda a sociedade devem compreender profundamente e refletir 
a respeito dessas implicações, assim como entender que não é possível confinar peixes com segurança total, ou sem riscos de escapes, mesmo que todo cuidado fosse tomado (o que via de regra não é o caso).

\section{Conclusão}

Há um consenso que a melhor maneira de se evitar os impactos negativos de espécies não-nativas é prevenir a sua introdução mesmo na ausência de evidências negativas decorrentes de uma introdução, a prudência deve prevalecer (Leprieur et al. 2009; referências dentro destes artigos), basicamente devido às dificuldades e custos associados à remoção de uma espécie indesejável. Dessa forma, o PL 5989/09 representa um profundo retrocesso à conservação da diversidade biológica das águas continentais brasileiras, e, portanto, aos bens e serviços ecossistêmicos e às gerações futuras. Lembramos que o Brasil é signatário da Convenção Internacional sobre Diversidade Biológica e, como tal, tem obrigações de, como destaca Artigo $8^{\circ}$ dessa convenção, "controlar e erradicar espécies não-nativas que possam interferir nos ecossistemas naturais e diminuir a biodiversidade local, além da adoção de medidas preventivas.”

Nuñez \& Pauchard (2010) sugerem que a insistência pelo cultivo de espécies não-nativas, a ampla desinformação sobre o assunto, assim como o abismo que separa o gestor público da comunidade científica, são características típicas de países em desenvolvimento. Diante do presente contexto, fica a pergunta: na perspectiva da gestão, do conhecimento e de sua aplicação de forma transdisciplinar, até quando continuaremos "subdesenvolvidos"? Aprovar uma lei que ameaça diretamente o patrimônio ambiental da Nação, mesmo à luz de opiniões técnicas contrárias, sugere que o modelo de desenvolvimento adotado não leva em consideração o meio ambiente em que a sociedade se insere e os recursos naturais das gerações futuras.

\section{Referências}

AES Tietê, 2007. Programa de manejo e conservação de bacias hidrográficas e reservatórios: Ictiofauna e qualidade de água. Relatório. AES Tietê, Eco Consultoria Ambiental. 364 p.

Agostinho AA et al., 2010. Reservoir fish stoking: when one plus one may be less than two. Natureza \& Conservação, 8:103-111. http://dx.doi.org/10.4322/natcon.00802001

Azevedo-Santos VM, Rigolin-Sá O \& Pelicice FM, 2011. Growing, losing or introducing? Cage aquaculture as a vector for the introduction of non-native fish in Furnas Reservoir, Minas Gerais, Brazil. Neotropical Ichthyology, 9(4):915-919. http://dx.doi.org/10.1590/S1679-62252011000400024

Brasil. 2009a. Lei $\mathrm{n}^{\circ} 11959$, de 29 de junho de 2009. Dispõe sobre a Política Nacional de Desenvolvimento Sustentável da Aquicultura e da Pesca, regula as atividades pesqueiras, revoga a Lei no 7.679, de 23 de novembro de 1988, e dispositivos do Decreto-Lei no 221, de 28 de fevereiro de 1967, e dá outras providências. Diário Oficial da República Federativa do Brasil, Brasília (2009 set.).

Brasil. 2009b. Projeto de lei n 5989, de 08 de setembro de 2009. Altera e acrescenta dispositivos à Lei no 11.959 , de 29 de junho de 2009, dispondo sobre a aquicultura de espécies autóctones, alóctones ou exóticas e sobre a obrigatoriedade de os proprietários ou concessionários de represas procederem à respectiva recomposição ambiental. Diário Oficial da República Federativa do Brasil, Brasília (2009 set.).

Canonico GC et al., 2005. The effects of introduced tilapias on native biodiversity. Aquatic Conservation: Marine and Freshwater Ecosystems, 15:463-483. http://dx.doi. org/10.1002/aqc.699

Cucherousset J \& Olden JD, 2011. Ecological impacts of non-native freshwater fishes. Fisheries, 36(5):215-230. http:// dx.doi.org/10.1080/03632415.2011.574578

Dempster T et al., 2004. Extensive aggregations of wild fish at coastal sea-cage fish farms. Hydrobiologia, 525:245-248. http://dx.doi.org/10.1023/B:HYDR.0000038870.13985.0f

Havel JE, Lee CE \& Vander Zanden J, 2005. Do reservoirs facilitate invasions into landscapes? BioScience, 55(6):518-525. http://dx.doi.org/10.1641/0006-3568(2005)055[0518:DRFI IL] 2.0.CO;2

Johnson PTJ, Olden JD \& Zanden MJV, 2008. Dam invaders: impoundments facilitate biological invasions into freshwaters. Frontiers in Ecology and the Environment, 6(7):357-363. http://dx.doi.org/10.1890/070156

Leprieur F et al., 2009. Scientific uncertainty and the assessment of risks posed by non-native freshwater fishes. Fish and Fisheries, 10:88-97. http://dx.doi.org/10.1111/j.1467-2979.2008.00314.x

Magalhães JLB, Casatti L \& Vitule JRS, 2011. Alterações no Código Florestal Brasileiro favorecerão espécies não-nativas de peixes de água doce. Natureza \& Conservação, 9:121-124. http://dx.doi.org/10.4322/natcon.2011.017

Metzger JP, 2010. O Código Florestal tem base científica? Natureza \& Conservação, 8(1):92-99. http://dx.doi. org/10.4322/natcon.00801017

Naylor RL, Williams SL \& Strong DR. 2001. Aquaculture - a gateway for exotic species. Science, 294:1655-1656. PMid:11721035. http://dx.doi.org/10.1126/science.1064875

Nuñez MA \& Pauchard A, 2010. Biological invasions in developing and developed countries: does one model fit all? Biological Invasions, 12:707-714. http://dx.doi.org/10.1007/ s10530-009-9517-1

Peeler EJ \& Feist SW, 2011. Human intervention in freshwater ecosystems drives disease emergence. Freshwater Biology, 56:705-716. http://dx.doi. org/10.1111/j.1365-2427.2011.02572.x

Zambrano L, Scheffer M \& Martínez-Ramos M, 2001. Catastrophic response of lakes to benthivorous fish introduction. Oikos, 94:344-350. http://dx.doi. org/10.1034/j.1600-0706.2001.940215.x 